\title{
Effects of Mindfulness-Based Stress Reduction on Health and Social Care Education: a Cohort-Controlled Study
}

\author{
Herman Hay Ming Lo ${ }^{1}$ (D) $\cdot$ Sowa $\mathrm{Ngai}^{1} \cdot \mathrm{Kong} \mathrm{Yam}^{1}$ \\ Accepted: 26 May 2021 / Published online: 10 June 2021 \\ (c) The Author(s), under exclusive licence to Springer Science+Business Media, LLC, part of Springer Nature 2021
}

\begin{abstract}
Objectives Mindfulness practice has been recommended as part of health and social care education and training because of its potential benefits in fostering clinical skills and attitudes, increasing self-care, and reducing the effect of stress in education and occupation. The objectives of this study were to evaluate the effects of a mindfulness-based stress reduction (MBSR) program on stress, physical distress, job burnout, work engagement, and empathy for health and social care education.

Methods Students $(N=124)$ from postgraduate programs in social work, counseling, and family therapy were recruited. Sixty-four students participated in an 8-week MBSR program as an elective course. Sixty students were recruited from other elective courses in the same cohort as control group participants. All participants completed self-report assessments. Results The results suggested that MBSR was associated with significant improvements in perceived efficacy and vigor and significant reductions in physical distress, total job burnout, emotional exhaustion, and depersonalization of clients compared with the control group.

Conclusions This study contributes to the growing body of literature highlighting the potential use of mindfulness practice to improve students' personal well-being and professional growth in health and social care education. Mindfulness practice should be further promoted in health and social care education and training.
\end{abstract}

Keywords Mindfulness $\cdot$ Healthcare $\cdot$ Social care $\cdot$ Education and training $\cdot$ Stress $\cdot$ Burnout $\cdot$ Employee engagement

Preparing to enter the health and social care profession is a stressful process, as during education and training, students must understand the complexity and difficulty of real-world practices. When supporting others, these helping professionals often serve the most needy and underprivileged members of society and encounter individuals or families affected by traumatic experiences of mental health, abuse, loss, grief, death, and different types of vulnerability (Newell \& MacNeil, 2010). Students must be prepared to work in a difficult environment, with high caseloads, lack of resources, shift work, low wages, and the pervasive effects of organizational constraints (Morse et al., 2012).

A review by Morse et al. (2012) suggested that between 21 and $67 \%$ of healthcare professionals exhibited different levels of burnout. Burnout is a state of physical and psychological exhaustion resulting from chronic exposure or involvement in human services (Pines \& Aronson, 1988),

Herman Hay Ming Lo

herman.lo@polyu.edu.hk

1 Department of Applied Social Sciences, The Hong Kong Polytechnic University, Hung Hom, Kowloon, Hong Kong conceptualized as a construct with three factors: emotional exhaustion, lacking personal accomplishment, and depersonalization (Maslach \& Jackson, 1981). Emotional exhaustion refers to feelings of emotionally overextended and exhausted by work. Lacking personal accomplishment refers to a lack of satisfaction and competence in working with people. Finally, depersonalization refers to impersonal responses to clients, coworkers, or work (Maslach \& Jackson, 1981). In addition to burnout, health and social care professionals may experience secondary traumatic stress and compassion fatigue (Newell \& MacNeil, 2010). In primary care settings, numerous studies and reviews have shown a significant association between poor staff well-being and poor patient safety outcomes (Welp \& Manser, 2016). Higher burnout is also associated with increased errors (Hall et al., 2016) and poor patient satisfaction (Salyers et al., 2017). Salyers et al. (2015) found that lower levels of personal accomplishment and depersonalization were significantly associated with lower overall quality of care and higher emotional exhaustion and depersonalization were significantly associated with lower work conscientiousness. 
Most postgraduate students in health and social care education work in human services or related areas. During their studies, practicums or field placements will be organized as part of the training of these professionals (e.g., Holden et al., 2011; Thompson \& Moffett, 2010). Inexperience, inadequate supervision, conflicting roles, and contextual demands can be additional challenges contributing to student distress (Giddings et al., 2007; Le Maistre \& Paré, 2004; Lloyd et al., 2002).

Mindfulness is a process of regulating attention to bring qualities of non-elaborative awareness to current experience and relating to one's experience with curiosity, experiential openness, and acceptance (Bishop et al., 2004). Two wellestablished mindfulness-based program (MBP) protocolsmindfulness-based stress reduction (MBSR) and mindfulness-based cognitive therapy (MBCT) - teach people to direct their attention nonjudgmentally to their body, feelings, and thoughts in the present moment in an 8-week duration (Kabat-Zinn, 1990; Segal et al., 2013). Meta-analyses have demonstrated that MBSR and MBCT can effectively relieve emotional symptoms and improve overall functioning in people with physical and mental health issues (Gu et al., 2015; Khoury et al., 2013). Evidence-based MBP has been widely applied in clinical populations, such as adults with depression, anxiety disorder, eating disorders, chronic health conditions, children, adolescents, the elderly with different types of mental health issues, couples with relationship problems, or even intimate partner violence.

Mindfulness practice has been recommended as part of health and social care education and training because of its potential benefits in fostering clinical skills and attitudes, increasing self-care, and reducing the effect of stress in education and occupation (Gockel, 2010). Two recent systematic reviews have supported the feasibility of MBP for university students, with mixed results. Daya and Hearn (2019) reviewed 12 studies of MBP with medical students and found that four out of seven studies reported significant improvement in symptoms of stress and five out of nine reported improvement in symptoms of depression. Three studies used burnout as the outcome measure, and only one of them reported significant improvement (Garneau et al., 2013). O'Driscoll et al. (2017) reviewed nine studies of MBP with health and social care undergraduate students, including studies based on MBSR or MBCT programs with a control-group design only. Only four studies reported a significant reduction in symptoms of stress and/or depression.

Moreover, these studies had certain limitations. First, the structure of the MBP varied across studies, most of them modified the intervention according to their university curriculum, and many either had shorter classes of $1.5 \mathrm{~h}$ or condensed the program into 6 weeks or less. Therefore, it is unclear whether their non-significant results can be attributed to the low intensity of the interventions. Second, the studies based on health and social care students often had a small sample size. The selected studies with a larger sample size (e.g., de Vibe et al., 2013; Rosenzweig et al., 2003) were based on medical students or a mix of medical and psychology students. Among the studies that were included in these two reviews, we found only two studies based on a standard MBSR intervention with healthcare students. Barbosa et al. (2013) studied the effects of MBSR on 13 healthcare students compared with 15 students as a control group and found significant improvements in anxiety and empathy. Song and Lindquist (2015) studied 44 nursing students and randomly assigned them to the MBSR or a waitlist control group. They found significant reductions in depression, anxiety, and stress and an increase in mindfulness. However, the generalizability of these studies may be limited by their small sample sizes. Finally, many studies of health and social care students have investigated the positive outcomes of helping qualities, such as work engagement and empathy. In the study by Barbosa et al. (2013), there was a significant improvement in empathy in the MBSR group compared with the control group, but no statistical difference was observed in the three subscales of burnout.

The aim of this study was to investigate the effectiveness of an 8-week MBSR program in reducing stress, physical distress, and burnout in health and social care students. We also examined whether the program had positive effects on their work engagement and empathy. We expected students in the intervention group to show a reduction in their stress, physical distress, and burnout and improvements in their work engagement and empathy, compared with students in the control group.

\section{Method}

\section{Participants}

This study was based on purposive sampling. Students from three postgraduate programs in social work, family therapy, or counseling at a Hong Kong university who enrolled in a mindfulness elective course were invited to participate in the study. They would join the intervention group involving an MBSR program as part of the curriculum. A matched control group was recruited from other elective courses of the mentioned three programs and from the same cohorts. Instructors introduced the purpose of the study during the first lecture of these courses and invited students to participate in the study on volunteer basis. One hundred and twenty-four students were recruited and participated in the study. Sixty-four of them joined the MBSR group, and sixty of them were recruited as control group participants. All of them gave their written consent and returned the questionnaire within the timeline. The majority were females 
(75.81\%). Almost half of the students were aged 21 to 30 (54.84\%), and the rest belonged to the 31-40 (35.48\%), $41-50(6.45 \%), 51-60(2.42 \%)$, and over $60(0.81 \%)$ age groups. Almost half of them were enrolled in the social work program (48.39\%), and the rest were enrolled in the family therapy program $(36.29 \%)$ and the counseling program $(15.32 \%)$. The majority were employed as social workers, administrative staff in non-government organizations, counselors and other helping professionals, and in other full-time positions $(85.48 \%)$, and the rest were full-time students without employment (14.52\%).

\section{Procedures}

This was a non-randomized, cohort-controlled study, conducted between 2017 and 2019. The participants were recruited from three cohorts. During the first mindfulness elective course, the first author gave a 45-min introduction to the MBSR program and the study procedures. Three authors introduced the purpose of the study in other courses of the programs and invited around 200 students to participate in the study, and finally sixty students joined the study on voluntary basis. There was no additional incentive to participate in the study.

Students from the intervention group would receive an envelope that contained the information of the study, consent form, and the questionnaire after the course orientation of the first lecture. They collected another envelope for the post-test questionnaire at the end of last lecture. Those from control group would collect the information sheet, consent form, and questionnaires through student email account after they indicated their interest to participate in the study. All students were requested to send their questionnaires back to the research assistant in 2 weeks after receiving the questionnaires. All demographic and pretest measures were collected during the first week of the academic term (time 0), and all post-test measures were collected again at the end of the semester (time 1). The first author taught the mindfulness elective, and the three authors taught other elective courses from the control group. All courses were taught on face-toface basis. This study was approved by the authors' University Research Ethics Committee (HSEARS20170224009).

Intervention The MBSR program in this study consisted of eight classes, meeting $2.5 \mathrm{~h}$ per week. The program was developed by Jon Kabat-Zinn and colleagues at the University of Massachusetts (Kabat-Zinn, 1990). The study followed the MBSR curriculum guide developed in 2017 (Santorelli et al., 2017). MBSR includes both experiential and didactic elements that focus on training in mindfulness-based meditative practices. The experiential elements involve sitting meditation (concentration of attention to the sensations of breathing while remaining open to other sensory events and to bodily sensations, thoughts, and emotions), body scan (a progressive movement of attention through the body from toe to head), mindful stretching (stretches and postures designed to enhance mindful body awareness), loving-kindness meditation (practices of compassion toward the self and others), and informal mindfulness practices (experiential practices bringing mindfulness into daily life, such as mindful eating and mindful walking). The didactic elements include inquiries with the participants to reveal and bring automated patterns of thoughts and feelings into conscious awareness. Home practice was strongly emphasized during the course. The instructor provided 40-min standard version and 20-min brief version audio files as guidance and encouraged students to practice between classes on regular basis. Students were not required to submit weekly log, but a course assignment was included to review their personal practice and learning during the 8 weeks. The 7-h day retreat was an optional additional learning activity for students, as it took place outside of the regular study hours of the course curriculum. Students could sign up and joined the retreat on a voluntary basis.

The MBSR instructor (the first author) received professional training from the Center for Mindfulness in Massachusetts, USA, and has taught MBSR/MBCT for 13 years. He followed the content and format of the MBSR curriculum guide and received clinical supervision recognized by the Center for Mindfulness. For each of the three MBSR courses in this study, two clinical supervision sessions were organized to discuss practice issues in the teaching process. Video recordings were prepared during supervision to ensure program fidelity.

\section{Measures}

Stress The Perceived Stress Scale (PSS; Cohen \& Williamson, $1988 ; \mathrm{Ng}, 2013)$ is a 10 -item questionnaire rated on a 5-point Likert scale (1 representing never and 5 representing always) designed to assess the extent to which life situations are considered stressful. Sum of the items were calculated for two subscales which include perceived helplessness and perceived efficacy and the total score (Roberti et al., 2006). In this study, internal consistency was acceptable for the total score (Cronbach's $\alpha=0.71$ ) and the subscales (perceived helplessness, $\alpha=0.83$; perceived efficacy, $\alpha=0.79$ ).

Burnout The Maslach Burnout Inventory (MBI; Maslach \& Jackson, 1981; Tang, 1998) is a 19-item questionnaire rated on a 5-point Likert scale designed to assess the frequency of symptoms of burnout in three domains: emotional exhaustion, depersonalization, and lack of personal accomplishment. A score of 0 represent very frequent, and a score of 5 represents very infrequent. Sum of the items were calculated 
for three subscales and the total score. Its internal consistency in this study was good for the total score $(\alpha=0.80)$ and the subscales (emotional exhaustion, $\alpha=0.84$; depersonalization, $\alpha=0.93$; lack of personal accomplishment, $\alpha=0.84$ ).

Work Engagement The short version of the Utrecht Work Engagement Scale (UWES; Fong \& Ng, 2012; Schaufeli et al., 2006) is a 9-item questionnaire rated on a 7-point Likert scale designed to assess the extent of work engagement in three domains: vigor, dedication, and absorption. A score of 0 represents never, and a score of 6 represents always or every day. Sum of the items were calculated for three subscales and the total score. Its internal consistency in this study was acceptable for the total score $(\alpha=0.91)$ and the subscales (vigor, $\alpha=0.78$; dedication, $\alpha=0.86$; absorption, $\alpha=0.73$ ),

Physical Distress The physical distress subscale of the BodyMind-Spirit Well-Being Inventory (BMSWBI; Ng et al., 2005) is a 14-item questionnaire rated on an 11-point Likert scale designed to assess symptoms of physical distress, such as headache, chest pain, and fatigue. A score of 0 represents no distress, and a score of 10 represents in extreme distress. Scores of the 14 items were added to calculate the score for physical distress. Its internal consistency in this study was $\operatorname{good}(\alpha=0.88)$.

Empathy The empathy subscale of the Interpersonal Reactivity Index (IRI; Davis, 1980; Siu \& Shek, 2005) is a 12-item questionnaire on a 5-point Likert scale designed to assess sensitivity to the experiences of others. A score of 0 represents low level of empathy, and a score of 4 represents high level of empathy. Scores of the 12 items were added to calculate the score for empathy. Its internal consistency in this study was acceptable $(\alpha=0.68)$.

Home Practice and Participation in the Day Retreat For this post-test questionnaire, we invited the participants in the MBSR group to report the average time (in minutes) per week spent in home practice during the 8-week program and to indicate whether they had attended the day retreat.

\section{Data Analyses}

Chi-square tests were conducted to analyze betweengroup differences in demographic variables at baseline. The intervention effect was evaluated by comparing the intervention (MBSR) and control groups (students from the same cohort). To test the hypotheses, $2 \times 2$ ANOVAs were performed, using the pretest and post-test scores as the within-group factor and the group variable (MBSR vs. control) as the between-group factor. All analyses followed the intention-to-treat approach. Missing values were handled with multiple imputation procedure (Sterne et al., 2009). All results were considered significant at $p<0.05$. In the case of significant results, the effect sizes were calculated. Cohen (1988) suggested that a $d$ value of 0.2 should be considered a small effect size, 0.5 a medium effect size, and 0.8 a large effect size.

The effects of the intensity of mindfulness practice, measured by the students' self-reported home practice and participation in the day retreat and demographic variables (sex and age), were analyzed after controlling their perceived stress, burnout, work engagement, physical distress, and empathy at time 0 , using linear regression analyses. All data analyses were performed with SPSS 23.0.

\section{Results}

We conducted intention-to-treat (ITT) analyses on data from all participants (Gupta, 2011). The Chi-square test results showed that the students in the intervention and control groups did not differ significantly on any of the demographic measures at baseline (all $p>0.05$, see Table 1).

To examine the effects of MBSR on the outcome variables, $2 \times 2$ ANOVAs were conducted. The group $\times$ time interactions were significant for PSS perceived efficacy $(F=5.72, p<0.05, d=-0.24)$ and BMSWBI physical distress $(F=5.61, p<0.05, d=0.30)$. The group $\times$ time interactions were also significant for MBI total score $(F=8.06$, $p<0.01, d=0.28)$ and two of the subscales, emotional exhaustion $(F=6.71, p<0.05, d=0.31)$ and depersonalization of client $(F=5.87, p<0.05, d=0.16)$, and UWES vigor $(F=4.00, p<0.05, d=-0.20)$. The results indicated that the participants in the intervention group had greater improvements than those in the control group for these variables (Table 2).

Although the MBSR group showed positive changes in perceived helplessness, dedication, and absorption in work engagement and empathy in the expected direction, the group $\times$ time effects were not significant for PSS total score, PSS perceived helplessness, MBI lack of personal accomplishment, UWES total score, UWES dedication, UWES absorption, and IRI empathy (all $p>0.05$ ).

Students from MBSR group reported spending $151 \mathrm{~min}$ per week (SD: $112 \mathrm{~min}$ ) for home practice. Thirty-nine out of $64(60.9 \%)$ of the students in MBSR group joined the day retreat. For burnout, we found a significant effect of sex $(\beta=0.32, p=0.029)$, and females were more likely to have a higher MBI score at time 1, using linear regression analyses. For other outcomes, no significant predictor was identified (all $p>0.05$ ). Time spent in home practice and participation of day retreat were not significant predictor of all outcomes ( $p>0.05)$. 
Table 1 Demographics of the participants

\begin{tabular}{|c|c|c|c|c|c|c|c|c|c|}
\hline & & \multicolumn{2}{|c|}{$\begin{array}{l}\text { All } \\
N=124\end{array}$} & \multicolumn{2}{|c|}{$\begin{array}{l}\text { MBSR } \\
n=64\end{array}$} & \multicolumn{2}{|c|}{$\begin{array}{l}\text { Control } \\
n=60\end{array}$} & \multirow[b]{2}{*}{$\chi^{2}$} & \multirow[b]{2}{*}{$p$} \\
\hline & & $\mathrm{n}$ & $\%$ & $\mathrm{n}$ & $\%$ & $\mathrm{n}$ & $\%$ & & \\
\hline \multirow[t]{2}{*}{ Gender } & Male & 30 & 24.19 & 17 & 26.56 & 13 & 21.67 & 0.405 & 0.525 \\
\hline & Female & 94 & 75.81 & 47 & 73.44 & 47 & 78.33 & & \\
\hline \multirow[t]{5}{*}{ Age } & $21-30$ & 68 & 54.84 & 36 & 56.25 & 32 & 53.33 & 2.033 & 0.730 \\
\hline & $31-40$ & 44 & 35.48 & 21 & 32.81 & 23 & 38.33 & & \\
\hline & $41-50$ & 8 & 6.45 & 5 & 7.81 & 3 & 5.00 & & \\
\hline & $51-60$ & 3 & 2.42 & 1 & 1.56 & 2 & 3.33 & & \\
\hline & $>60$ & 1 & 0.81 & 1 & 1.56 & 0 & 0.00 & & \\
\hline \multirow[t]{3}{*}{ Program } & Social work & 60 & 48.39 & 29 & 45.31 & 31 & 51.67 & 1.277 & 0.528 \\
\hline & Family therapy & 45 & 36.29 & 23 & 35.94 & 22 & 36.67 & & \\
\hline & Counseling & 19 & 15.32 & 12 & 18.75 & 7 & 11.67 & & \\
\hline \multirow[t]{6}{*}{ Job } & Social worker & 24 & 19.35 & 16 & 25.00 & 8 & 13.33 & 9.097 & 0.105 \\
\hline & Counselor & 11 & 8.87 & 7 & 10.94 & 4 & 6.67 & & \\
\hline & NGO administrative staff & 26 & 20.97 & 15 & 23.44 & 11 & 18.33 & & \\
\hline & Other helping professionals & 13 & 10.48 & 3 & 4.69 & 10 & 16.67 & & \\
\hline & $\begin{array}{l}\text { Employment other than human } \\
\text { service organizations }\end{array}$ & 32 & 25.81 & 13 & 20.31 & 19 & 31.67 & & \\
\hline & Students without employment & 18 & 14.52 & 10 & 15.63 & 8 & 13.33 & & \\
\hline
\end{tabular}

Note: $M B S R$ mindfulness-based stress reduction program, $N G O$ non-governmental organization

\section{Discussion}

Supporting our hypotheses, this study found that the MBSR program was associated with improvements in perceived efficacy; physical distress; burnout, in particular emotional exhaustion and depersonalization; and vigor, a subscale of work engagement, among health and social care students compared with the cohort controls. Although all effects can be considered small, the superior effect of MBSR compared with the active control suggests that MBSR or similar programs should be promoted for healthcare and social care education programs.

Table 2 Measures over time for intervention group and control group

\begin{tabular}{|c|c|c|c|c|c|c|c|c|c|c|c|c|c|c|c|c|}
\hline \multirow[b]{3}{*}{ Variable } & \multicolumn{6}{|c|}{ Treatment group } & \multicolumn{6}{|c|}{ Control group } & \multirow[b]{3}{*}{$F$} & \multirow[b]{3}{*}{$d f$} & \multirow[b]{3}{*}{$p$} & \multirow[b]{3}{*}{$d$} \\
\hline & \multicolumn{3}{|c|}{ Pretest } & \multicolumn{3}{|c|}{ Post-test } & \multicolumn{3}{|c|}{ Pretest } & \multicolumn{3}{|c|}{ Post-test } & & & & \\
\hline & $\mathrm{n}$ & Mean & SD & $\mathrm{n}$ & Mean & SD & $\mathrm{n}$ & Mean & SD & $\mathrm{n}$ & Mean & SD & & & & \\
\hline Perceived Stress & 64 & 21.08 & 4.65 & 64 & 19.84 & 5.14 & 60 & 20.08 & 5.52 & 60 & 19.87 & 5.49 & 2.102 & 122.1 & 0.150 & \\
\hline Perceived Helplessness & 64 & 14.13 & 3.66 & 64 & 13.47 & 4.00 & 60 & 13.38 & 3.60 & 60 & 12.88 & 3.38 & 0.084 & 122.1 & 0.773 & \\
\hline Perceived efficacy & 64 & 9.05 & 2.37 & 64 & 9.63 & 2.59 & 60 & 9.30 & 2.96 & 60 & 9.02 & 3.02 & 5.724 & 122.1 & $0.018^{*}$ & -0.24 \\
\hline Physical distress & 64 & 36.53 & 19.75 & 64 & 30.66 & 20.26 & 60 & 30.80 & 19.78 & 60 & 30.13 & 19.49 & 5.611 & 122.1 & $0.019^{*}$ & 0.30 \\
\hline Burnout & 57 & 3.07 & 0.60 & 57 & 2.92 & 0.46 & 56 & 2.99 & 0.55 & 56 & 3.06 & 0.62 & 8.059 & 111.1 & $0.005 * *$ & 0.28 \\
\hline Emotional exhaustion & 57 & 3.11 & 0.86 & 57 & 2.86 & 0.78 & 56 & 3.02 & 0.87 & 56 & 3.08 & 0.95 & 6.705 & 111.1 & $0.011^{*}$ & 0.31 \\
\hline Lack of personal accomplishment & 57 & 3.21 & 0.81 & 57 & 3.21 & 0.85 & 56 & 2.92 & 0.68 & 56 & 2.95 & 0.76 & 0.061 & 111.1 & 0.805 & \\
\hline Depersonalization of client & 57 & 2.90 & 1.26 & 57 & 2.70 & 1.23 & 56 & 3.03 & 1.25 & 56 & 3.14 & 1.27 & 5.867 & 111.1 & $0.017 *$ & 0.16 \\
\hline Work engagement & 62 & 3.29 & 1.01 & 62 & 3.49 & 0.92 & 59 & 3.11 & 0.99 & 59 & 3.10 & 1.05 & 2.901 & 119.1 & 0.091 & \\
\hline Vigor & 62 & 3.42 & 1.09 & 62 & 3.63 & 0.98 & 59 & 3.22 & 1.05 & 59 & 3.15 & 1.14 & 4.001 & 119.1 & $0.048^{*}$ & -0.20 \\
\hline Dedication & 62 & 3.62 & 1.11 & 62 & 3.85 & 1.03 & 59 & 3.58 & 1.17 & 59 & 3.57 & 1.17 & 2.583 & 119.1 & 0.111 & \\
\hline Absorption & 62 & 2.83 & 1.10 & 62 & 2.97 & 1.12 & 59 & 2.54 & 1.15 & 59 & 2.59 & 1.23 & 0.343 & 119.1 & 0.559 & \\
\hline Empathy & 64 & 31.22 & 4.04 & 64 & 32.05 & 4.52 & 60 & 30.85 & 4.49 & 60 & 30.67 & 4.56 & 2.608 & 122.1 & 0.109 & \\
\hline
\end{tabular}

${ }^{*} p<.05 ; * * p<.01$ 
This study confirmed previous results in the literature on the benefits of MBP on self-efficacy, a subscale of perceived stress (Hou et al., 2014). Although a recent study reported a non-significant correlation of self-efficacy and mindfulness (Lo, 2021), mindfulness practice may promote a non-judgmental attitude in cognitive processing that can facilitate emotion regulation and reduce stress resulting from challenges. Mindfulness promotes an understanding of the transient nature of thoughts, emotions, or external circumstances, which in turn can lead to a sense of competence and autonomy (Brown \& Ryan, 2003) or perceived self-control (Luberto et al., 2011). The non-significant effect of MBSR on overall perceived stress and perceived helplessness was slightly unexpected. We compared this result with previous studies and found that MBP led to a reduction in perceived stress (PSS) in only one study (Phang et al., 2015). Other studies either adopted a different stress scale (Shapiro et al., 1998) or did not report significant result (Hou et al., 2014). In addition, Ng's (2013) Chinese PSS validation study found a weak inter-factor correlation between two subscales, perceived helplessness and self-efficacy, so future research should replicate this study using other stress outcome measures.

About $85 \%$ of the participants worked full-time, and $60 \%$ were working in human service organizations and studying part-time during the study. MBSR significantly reduced their symptoms of burnout, especially for emotional exhaustion and depersonalization of clients. While some systematic reviews have supported the effectiveness of MBP in reducing job burnout (e.g., Luken \& Sammons, 2016), another review by Daya and Hearn (2019) found that few studies explored the effects of MBP on burnout in medical students, and two studies with large sample sizes reported no significant effect on the medical student population (de Vibe et al., 2013; Rosenzweig et al., 2003). There are two possible explanations for these contradictory results. First, medical students and health and social care students have different education and training needs. Indeed, the nature of the work and the training module in health and social care education involves more complex interpersonal dynamics and individual and family traumatic experiences, for which mindfulness training may be particularly useful in regulating stress and reducing the risk of burnout. Second, students enrolled in compulsory MBP are likely to experience psychological barriers and have poor home practice compliance (Wong, 2016). Many health and social care students intend to apply the mindfulness skills in future professional practice, and they also believe that mindfulness training can enhance their competence in helping. Therefore, in this study, all students enrolled in MBSR on a voluntary basis, and their positive outcomes can be attributed to their high level of motivation. Future studies should include a personal motivation variable to verify this speculation.
Although some intervention programs have been shown to be effective in promoting work engagement (see Knight et al., 2017), very few studies have investigated the effects of MBP in this area using a rigorous study design (Klatt et al., 2015). It is likely that people with a more attentive mental attitude are less prone to distraction and show a higher level of engagement in the tasks at hand. More indirectly, it is possible that more accepting and non-reactive emotion regulation strategies are beneficial in the workplace and contribute to a better balance of work and life (Malinowski \& Lim, 2015). Although vigor was the only work engagement subscale that showed a significant improvement, it has been shown to be the component of work engagement most sensitive to the intervention effect (Knight et al., 2017). Modification of the MBSR curriculum and integration with other employment support interventions may be necessary if more positive effects on work engagement are expected.

The positive reduction in physical distress after MBSR adds evidence for the effectiveness of MBP in students, as this outcome has not been identified in previous studies with students. However, the literature has shown that MBP can have a large effect size in terms of reducing physical distress in people with symptoms of depression and anxiety (Lo et al., 2015). The recent review by Crewell et al. (2019) suggested three possible mechanisms of MBP and physical health through biological pathways (including promotion of stress regulation and reduction of stress reactivity in the brain), psychological pathways (including attention regulation and acceptance), and health behavior pathways (including reduction of addictive behaviors and promotion of healthy diet, sleep, and related behaviors).

The non-significant improvement in empathy after MBSR may be due to the selected measure, which was originally developed for general interpersonal relationships instead of helping qualities. Future studies should use a specific measure of empathy and investigate the effect of MBSR on empathy.

We found a significant effect of sex in burnout, and females were more likely to report higher burnout scores at post-intervention. A previous study suggested that gender effect on burnout in helping professionals is an interaction effect of empathy and work accomplishment (Williams, 1989). Further studies should explore the prevention and intervention effect with a refined study design.

Unexpectedly, we did not find an association of home practice and participation in a day retreat with outcomes in this study. Previous reviews suggest a positive relationship in home practice and intervention outcomes (Crane et al., 2014; Parsons et al., 2017). We recommend further study investigate the role of home practice in health and social care students, as their needs may be different from clinical populations. Improvement in measures of home practice such as ecological momentary assessment, instead 
of relying on self-reported measures, should be considered (Ruscio et al., 2016).

\section{Limitations and Implications for Future Research}

We have identified five limitations in this study. First, this was a cohort-controlled study, not a randomized controlled trial. No significant difference between the participants in the intervention group and the control group was found at baseline, but due to the lack of randomization, potential group differences were not controlled, which can be a confounding variable. Second, follow-up assessments were not included to determine whether the positive effects of the MBSR program were sustainable. It would be useful to know whether the benefits of MBSR can last after the program. Third, the study is not based on representative sampling. The sample size was not large, and we did not calculate power analysis before the study. The generalizability to similar student population may be undermined. Fourth, the outcome measure for empathy reports relatively low internal consistency, with a Cronbach's alpha of 0.68 . It is developed for measuring empathy in general interpersonal relationship. Further study may select a scale that is specifically developed for measuring the empathy for helping professionals. Fifth, we did not study the impact of attendance due to the incomplete data in this aspect. Further studies may study the effect of such potential moderator. Lastly, in this study, we rely on self-reported measures, and it is likely to have method bias (Podsakoff et al., 2012). As the study assessed multiple constructs using a common method relying on multiple-item scales presented within the same survey, it would lead to spurious effects due to the measurement instruments rather than to the constructs being measured. When participants are asked to report their perceptions on several related constructs in the same study, there is a potential method bias due to spurious correlations among the items measuring these constructs owing to response styles, social desirability, or priming effects. Future studies should include multiple measures other than self-reported scales to control the method bias.

Finally, we would like to propose two other directions or strategies for future research. First, mindfulness training is increasingly recognized as a pedagogy that can facilitate the development of clinical knowledge and practice skills (Gockel \& Deng, 2016). Many skills supported by mindfulness training, such as attention, cognitive flexibility, compassion, affect tolerance, or emotion regulation, should be assessed as outcomes or mediating variables in future studies. Second, biomarkers, such as cortisol and heart rate variability, have been used in some university student interventions and MBP studies (Shearer et al., 2016; Zimmaro et al., 2016). Future studies should consider using biomarkers in combination with self-reported measures to further promote the results of this area of research.

Author Contribution HHML: designed and executed the study, conducted data analysis, and prepared the manuscript. SN: collaborated with the design and assisted in recruitment and editing of the manuscript. KY: assisted in recruitment and editing of the manuscript.

\section{Declarations}

Ethics Approval This study was approved by The Hong Kong Polytechnic University, University Research Ethics Committee (HSEARS20170224009).

Informed Consent All participants provided written informed consent.

Conflict of Interest The authors declare no competing interests.

\section{References}

Barbosa, P., Raymond, G., Zlotnick, C., Wilk, J., Toomey, R., \& Mitchell, J. (2013). Mindfulness-based stress reduction training is associated with greater empathy and reduced anxiety for graduate healthcare students. Education for Health, 26, 9-14.

Bishop, S. R., Lau, M., Shapiro, S., Carlson, L., Anderson, N. D., Carmody, J., Segal, Z. V., Abbey, S., Speca, M., Velting, D., \& Devins, G. (2004). Mindfulness: A proposed operational definition. Clinical Psychology: Science and Practice, 11(3), 230-241.

Brown, K. W., \& Ryan, R. M. (2003). The benefits of being present: Mindfulness and its role in psychological well-being. Journal of Personality and Social Psychology, 84, 822-848.

Cohen, J. (1988). Statistical power analysis for the behavioral sciences (2nd ed.). Lawrence Earlbaum Associates.

Cohen, S., \& Williamson, G. (1988). Perceived stress in a probability sample of the United States. In S. Spacapan \& S. Oskamp (Eds.), The Social Psychology of Health: Claremont Symposium on Applied Social Psychology (pp. 31-67). Sage.

Crane, C., Crane, R., Eames, C., Fennell, M. J. V., Silverton, S., Williams, J. M. G., \& Bernhofer, T. (2014). The effects of amount of home meditation practice in mindfulness based cognitive therapy on hazard of relapse to depression in the Staying Well after Depression Trial. Behaviour Research and Therapy, 63, 17-24.

Crewell, J. D., Lindsay, E. K., Villalba, D. K., \& Chin, B. (2019). Mindfulness training and physical health: Mechanisms and outcomes. Psychosomatic Medicine, 81(3), 224-232.

Davis, M. (1980). A multidimensional approach to individual differences in empathy. Catalog of Selected Documents in Psychology, 10, 1-17.

Daya, Z., \& Hearn, J. H. (2019). Mindfulness interventions in medical education: A systematic review of their impact on medical student stress, depression, fatigue and burnout. Medical Teacher, 40(2), 146-153.

de Vibe, M., Solhaug, I., Tyssen, R., Friborg, O., Rosenvinge, J. H., Sørlie, T., \& Bjørndal, A. (2013). Mindfulness training for stress management: A randomised controlled study of medical and psychology students. BMC Medical Education, 13, 488. https://doi.org/10.1186/1472-6920-13-107

Fong, T. C. T., \& Ng, S. M. (2012). Measuring engagement at work: Validation of the Chinese version of the Utrecht Work Engagement Scale. International Journal of Behavioral Medicine, 19, 391-397. 
Garneau, K., Hutchinson, T., Zhao, Q., \& Dobkin, P. (2013). Cultivating person centered medicine in future physicians. European Journal for Person Centered Healthcare, 1:468.

Giddings, M. M., Cleveland, P. H., \& Smith, C. H. (2007). Responding to inadequate supervision: A model promoting integration for post-MSW practitioners. The Clinical Supervisor, 25, $105-126$.

Gockel, A. (2010). The promise of mindfulness for clinical practice education. Smith College Studies in Social Work, 80, 248-268.

Gockel, A., \& Deng, X. (2016). Mindfulness training as social work pedagogy: Exploring benefits, challenges, and issues for consideration in integrating mindfulness into social work education. Journal of Religion \& Spirituality in Social Work: Social Thought, 35, 222-244.

Gu, J., Strauss, C., Bond, R., \& Cavanagh, K. (2015). How do mindfulness-based cognitive therapy and mindfulness-based stress reduction improve mental health and wellbeing? A systematic review and meta-analysis of mediation studies. Clinical Psychology Review, 37, 1-12.

Gupta, S. K. (2011). Intention-to-treat concept: A review. Perspectives in Clinical Research, 2, 109-112.

Hall, L. H., Johnson, J., Watt, I., Tsipa, A., \& O’Connor, D. B. (2016). Healthcare staff wellbeing, burnout, and patient safety: A systematic review. PLoS ONE, 11: e0159015.

Holden, G., Barker, K., Rosenberg, G., Kuppens, S., \& Ferrell, L. W. (2011). The signature pedagogy of social work? An investigation of the evidence. Research on Social Work Practice, 21, 363-372.

Hou, J., Wong, S. Y. S., Yip, B. H. K., Hung, A. T. F., Lo, H. H. M., Chan, P. H. S., Lo, C. S. L., Kwok, T. C. Y., Tang, W. K., Mak, W. W. S., Mercer, S. W., \& Ma, S. H. (2014). The effects of mindfulness-based stress reduction program on the mental health of family caregivers: A randomized controlled trial. Psychotherapy and Psychosomatics, 83(1), 45-53.

Kabat-Zinn, J. (1990). Full catastrophe living: Using the wisdom of your body and mind to face stress, pain and illness. Delacourt.

Khoury, B., Lecomte, T., Fortin, G., Masse, M., Therien, P., Bouchard, V., Chapleau, M.-A., Paquin, K., \& Hofmann, S. G. (2013). Mindfulness-based therapy: A comprehensive meta-analysis. Clinical Psychology Review, 33, 763-771.

Klatt, M., Steinberg, B., \& Duchemin, A. (2015). Mindfulness in Motion (MIM): An onsite mindfulness-based intervention (MBI) for chronically high stress work environments to increase resiliency and work engagement. Journal of Visualized Experiments, $101,1-11$.

Knight, C., Patterson, M., \& Dawson, J. (2017). Building work engagement: A systematic review and meta-analysis investigating the effectiveness of work engagement interventions. Journal of Organizational Behavior, 38, 792-812.

Le Maistre, C., \& Paré, A. (2004). Learning in two communities: The challenge for universities and workplaces. Journal of Workplace Learning, 16, 44-52.

Lloyd, C., King, R., \& Chenoweth, L. (2002). Social work, stress and burnout: A review. Journal of Mental Health, 11(3), 255-265.

Lo, H. H. M. (2021). Quality of life among adolescents in Hong Kong: General and gender-specific effects of self-efficacy and mindfulness. Applied Research in Quality of Life. https://doi.org/10.1007/ s11482-021-09914-w.

Lo, H. H. M., Ng, S. M., \& Chan, C. L. W. (2015). Evaluating compassion-mindfulness therapy for recurrent depression and anxiety: A randomized control trial. Research on Social Work Practice, 25, 715-725. https://doi.org/10.1177/1049731514537686

Luberto, C. M., McLeish, A. C., Zvolensky, M. J., \& Baer, R. A. (2011). Mindfulness skills and anxiety-related cognitive processes among young adult daily smokers: A pilot test. Mindfulness, 2, $129-136$.
Luken, M., \& Sammons, A. (2016). Systematic review of mindfulness practice for reducing job burnout. American Journal of Occupational Therapy, 70, 7002250020p1-7002250020p10.

Malinowski, P., \& Lim, H. J. (2015). Mindfulness at work: Positive affect, hope, and optimism mediate the relationship between dispositional mindfulness, work engagement, and well-being. Mindfulness, 6, 1250-1262.

Maslach, C., \& Jackson, S. E. (1981). The measurement of experienced burnout. Journal of Organizational Behavior, 2, 99-113.

Morse, G., Salyers, M. P., Rollins, A. L., Monroe-DeVita, M., \& Pfahler, C. (2012). Burnout in mental health services: A review of the problem and its remediation. Administration and Policy in Mental Health and Mental Health Services Research, 39, 341-352.

Newell, J. M., \& MacNeil, G. A. (2010). Professional burnout, vicarious trauma, secondary traumatic stress, and compassion fatigue. Best Practices in Mental Health, 6, 57-68.

$\mathrm{Ng}, \mathrm{S}$. M. (2013). Validation of the 10-item Chinese perceived stress scale in elderly service workers: One-factor versus two-factor structure. BMC Psychology, 1, 9.

Ng, S. M., Yau, J. K., Chan, C. L., Chan, C. H., \& Ho, D. Y. (2005). The measurement of body-mind-spirit well-being: Toward multidimensionality and transcultural applicability. Social Work in Health Care, 41, 33-52.

O’Driscoll, M., Byrne, S., Mc Gillicuddy, A., Lambert, S., \& Sahm, L. J. (2017). The effects of mindfulness-based interventions for health and social care undergraduate students - A systematic review of the literature. Psychology, Health \& Medicine, 22(7), 851-865.

Parsons, C. E., Crane, C., Parsons, L. J., Fjorback, L. O., \& Kuyken, W. (2017). Home practice in mindfulness-based cognitive therapy and mindfulness-based stress reduction: A systematic review and meta-analysis of participants' mindfulness practice and its association with outcomes. Behaviour Research and Therapy, 95, 29-41.

Phang, C. K., Mukhtar, F., Ibrahim, N., Keng, S.-L., \& Sidik, S. M. (2015). Effects of a brief mindfulness-based intervention program for stress management among medical students: The MindfulGym randomized controlled study. Advances in Health Sciences Education, 20, 1115-1134.

Pines, A., \& Aronson, E. (1988). Career burnout: Causes and cures. Free Press.

Podsakoff, P. M., MacKenzie, S. B., \& Podsakoff, N. P. (2012). Sources of method bias in social science research and recommendations on how to control it. Annual Review of Psychology, 63, 539-569.

Roberti, J. W., Harrington, L. N., \& Storch, E. A. (2006). Further psychometric support for the 10-item version of the perceived stress scale. Journal of College Counseling, 9, 135-147.

Rosenzweig, S., Reibel, D. K., Greeson, J. M., Brainard, G. C., \& Hojat, M. (2003). Mindfulness-based stress reduction lowers psychological distress in medical students. Teaching and Learning in Medicine, 15, 88-92.

Ruscio, A. C., Muench, C., Brede, E., Maclntyre, J., \& Waters, A. J. (2016). Administration and assessment of brief mindfulness practice in the field: A feasibility study using ecological momentary assessment. Mindfulness, 7, 988-999.

Salyers, M. P., Bonfils, K. A., Luther, L., Firmin, R. L., White, D. A., Adams, E. L., \& Rollins, A. L. (2017). The relationship between professional burnout and quality and safety in healthcare: A metaanalysis. Journal of General Internal Medicine, 32, 475-482.

Salyers, M. P., Fukui, S., Rollins, A. L., Firmin, R., Gearhart, T., Noll, J. P., Williams, S., \& Davis, C. J. (2015). Burnout and selfreported quality of care in community mental health. Administration and Policy in Mental Health and Mental Health Services Research, 42, 61-69. 
Santorelli, S. F., Meleo-Meyer, F., Koerbel, L., \& Kabat-Zinn, J. (2017). Mindfulness-based stress reduction (MBSR) authorized curriculum guide. Center for Mindfulness in Medicine, Health Care, and Society, University of Massachusetts Medical School.

Schaufeli, W. B., Bakker, A. B., \& Salanova, M. (2006). The measurement of work engagement with a short questionnaire: A crossnational study. Educational and Psychological Measurement, 66, 701-716.

Segal, Z. V., Teasdale, J. D., \& Williams, J. M. G. (2013). Mindfulnessbased cognitive therapy for depression (2nd ed.). Guilford.

Shapiro, S. L., Schwartz, G. E., \& Bonner, G. (1998). Effects of mindfulness-based stress reduction on medical and premedical students. Journal of Behavioral Medicine, 21, 581-599.

Shearer, A., Hunt, M., Chowdhury, M., \& Nicol, L. (2016). Effects of a brief mindfulness meditation intervention on student stress and heart rate variability. International Journal of Stress Management, 23(2), 232-254.

Siu, A. M., \& Shek, D. T. (2005). Validation of the interpersonal reactivity index in a Chinese context. Research on Social Work Practice, $15,118-126$.

Song, Y., \& Lindquist, R. (2015). Effects of mindfulness-based stress reduction on depression, anxiety, stress and mindfulness in Korean nursing students. Nurse Education Today, 35, 86-90.

Sterne, J. A. C., White, I. R., Carlin, J. B., Spratt, M., Royston, P., Kenward, M. G., Wood, A. M., \& Carpenter, J. R. (2009). Multiple imputation for missing data in epidemiological and clinical research: Potential and pitfalls. BMJ, 338, b2393. https://doi.org/ 10.1136/bmj.b2393
Tang, C. S. K. (1998). Assessment of burnout for Chinese human service professionals: A study of factorial validity and invariance. Journal of Clinical Psychology, 54, 55-58.

Thompson, J. M., \& Moffett, N. L. (2010). Clinical preparation and supervision of professional school counselors. Journal of School Counseling, 8, n30.

Welp, A., \& Manser, T. (2016). Integrating teamwork, clinician occupational well-being and patient safety- Development of a conceptual framework based on a systematic review. BMC Health Services Research, 16, 281.

Williams, C. A. (1989). Empathy and burnout in male and female helping professionals. Research in Nursing \& Health, 12, 169-178.

Wong, V. P. Y. (2016). On becoming a mindful practitioner: A mixed methods study of students' perceptions and their psychological changes through mindfulness training in a medical humanities curriculum. Unpublished PhD Dissertation.

Zimmaro, L. A., Salmon, P., Naidu, H., Rowe, J., Phillips, K., Rebholz, W. N., Giese-Davis, J., Cash, E., Dreeben, S. J., Bayley-Veloso, R., Jablonski, M. E., Hicks, A., Siwik, C., \& Sephton, S. E. (2016). Association of dispositional mindfulness with stress, cortisol, and well-being among university undergraduate students. Mindfulness, $7,874-885$.

Publisher's Note Springer Nature remains neutral with regard to jurisdictional claims in published maps and institutional affiliations. 